\title{
BREVE INTRODUÇÃo À ANÁLISE DO DISCURSO DE JAMES PAUL GEE
}

\author{
Karen Cristiny de Andrade Correia ${ }^{1}$ \\ Universidade Federal de São João del-Rei
}

\section{RESUMO}

Este trabalho teve como objetivo realizar uma breve introdução ao pensamento de James Paul Gee no que diz respeito à Análise do Discurso. Ao desenvolver uma dissertação de mestrado ancorada em suas proposições, encontramos um único trabalho orientado por elas. Além disso, não há textos do autor sobre o discurso traduzidos para o português. Por isso, selecionamos conceitos fundamentais e elaboramos uma síntese de sua teoria. Na primeira seção, abordamos as noções de língua e de discursol Discurso e mostramos o papel da Análise do Discurso na sociedade; na segunda, explicitaremos a importância do contexto para essa abordagem e apresentaremos o conceito de modelos discursivos; por fim, discorreremos sobre o conceito de identidade, mostrando suas categorizações.

Palavras-chave: James Paul Gee. Análise Crítica do Discurso. Discurso. Modelos discursivos. Identidade.

\begin{abstract}
This paper aims to make a brief introduction to James Paul Gee's thought regarding Discourse Analysis. In developing a master's dissertation anchored in his propositions, we found a single work guided by them. In addition, there are no texts of the author on the discourse translated into Portuguese. Therefore, we select fundamental concepts and elaborate a synthesis of his theory. In the first section, we address the notions of language and discourse / Discourse and show the role of Discourse Analysis in society; in the second one, we will explain the importance of context for this approach and present the concept of discursive models; finally, we will discuss the concept of identity, showing its categorizations.
\end{abstract}

Keywords: James Paul Gee. Critical Discourse Analysis. Discourse. Discursive models. Identity.

\section{RESUMEN}

Este artículo tiene como objetivo hacer una breve introducción al pensamiento de James Paul Gee con respecto al Análisis del Discurso. Al desarrollar una tesis de maestría anclada en sus propuestas, encontramos un solo trabajo guiado por ellos. Además, no hay textos del autor sobre el discurso traducidos al portugués. Por lo tanto, seleccionamos conceptos fundamentales y elaboramos una síntesis de su teoría. En la primera sección, abordamos las nociones de lenguaje y discurso / Discurso y mostramos el papel del Análisis del Discurso en la sociedad; en el segundo, explicaremos la importancia del contexto para este enfoque y presentaremos el concepto de modelos discursivos; finalmente, discutiremos el concepto de identidad, mostrando sus categorizaciones.

Palabras clave: James Paul Gee. Análisis Crítico del Discurso. Discurso. Modelos discursivos. Identidad.

Recebido em: junho 2019

Aceito em: dezembro 2019

DOI: $\underline{10.26512 / \text { les.v20i2.25270 }}$

\section{INTRODUÇÃO}

\footnotetext{
${ }^{1}$ Graduada e mestra em Letras pela Universidade Federal de São João del-Rei (UFSJ). E-mail: kcacorreia@gmail.com.
} 
A despeito do grande número de pesquisas e programas de pós-graduação no campo da Análise do Discurso no Brasil, há uma escassez de estudos, em língua portuguesa, que se dediquem a ou se embasem na Análise do Discurso de James Paul Gee. É bastante comum encontrarmos trabalhos apoiados nas teorias do discurso de orientação francesa, bem como em outros autores da vertente anglo-saxã, como Norman Fairclough, Ruth Wodak, dentre outros. Todavia, James Paul Gee não costuma aparecer, ao menos no Brasil, como autor representativo do campo.

Isso foi percebido quando do desenvolvimento de uma dissertação de mestrado $(\text { CORREIA, 2017) })^{2}$. As teorias do autor sobre letramento e o ensino por meio de video game são amplamente difundidas, de forma que qualquer busca pelo seu nome nos bancos de dados acadêmicos nos leva a textos sobre tais aspectos. Todavia, não se pode perder de vista a relevância do autor no que diz respeito aos estudos sobre o discurso, o que o insere no campo da Análise Crítica do Discurso.

Durante o curso de mestrado, ao desenvolvermos uma pesquisa ancorada nesse quadro teórico, encontramos um único trabalho orientado por essa abordagem. Ainda assim, restringia-se ao conceito de identidade (cf. PAZ; FRADE, 2016). Não foram encontrados textos do autor acerca dessa temática traduzidos para o português, o que pode dificultar o acesso à teoria. Tendo em vista tal cenário e a importância das proposições de Gee no que concerne ao discurso, buscamos, no presente artigo, realizar uma breve introdução ao pensamento do pesquisador a respeito da Análise do Discurso com a finalidade de difundir tal perspectiva no âmbito dos estudos discursivos. Para cumprir com o objetivo aqui proposto, focalizaremos especialmente as noções de modelos Discursivos, discurso e identidade(s), tendo como base os trabalhos empreendidos em 1996, 2000, 2005 e 2011.

\section{LínguA, Discurso e ANÁLISE do Discurso}

Gee (2005) define a língua, e mais especificamente a língua em uso, como o domínio de estudo da Análise do Discurso. Ao contrário do que muitas vezes pensamos, a língua é forma de comunicação de informações, mas não só; e esta não é, para o autor, sua principal função. Na verdade, ele $(2005, \text { p. } 1)^{3}$ aponta não para uma função principal, mas duas, as quais estão completamente imbricadas, quais sejam: "apoiar o desempenho das atividades e identidades sociais

\footnotetext{
${ }^{2}$ Este trabalho é um recorte da dissertação de mestrado intitulada “"Na prática, a teoria é outra!': Uma análise discursiva sobre a responsabilidade social do professor de Português da Educação Básica”, desenvolvida na Universidade Federal de São João del-Rei (UFSJ) e financiada pela CAPES.

${ }^{3}$ Todas as citações de James Paul Gee são traduções minhas.
} 
e apoiar as filiações humanas a culturas, grupos sociais e instituições". ${ }^{4} \mathrm{O}$ imbricamento dessas funções se dá porque são as culturas, grupos e instituições que formam atividades e identidades sociais; ao mesmo tempo, porém, a existência da instituição depende de seu ordenamento e reordenamento a partir dessas mesmas identidades e atividades que a ela estão conectadas. Conforme as palavras de Gee (2005, p. 10), “[...] a linguagem e as instituições se arranjam mutuamente na existência em um processo recíproco através do tempo"5. Quando falamos, tentamos nos adequar à situação de comunicação; ao mesmo tempo, porém, é a nossa fala que cria a situação.

Gee (2005) explica que o analista de discurso deve ter interesse no modo como a língua é usada em um lugar e momento específicos para estabelecer atividades e identidades. Ou seja, deve estar interessado em analisar os discursos, que são essa língua em uso. Entretanto, não é apenas através da língua que construímos atividades e identidades ${ }^{6}$. A partir dessa ideia, Gee $(2005,2011)$ faz uma distinção entre discurso (com letra minúscula) e Discurso (com letra maiúscula), sendo que o último envolve pensar que no processo de significação que se dá entre uma pessoa e outra(s), nunca é apenas a língua que está em jogo. Para efetuar de forma eficaz tal processo, aquele que toma para si o discurso precisa comunicar ao outro a quem se dirige qual papel, qual identidade socialmente situada está sendo assumida naquele determinado momento, naquela situação de fala, e a língua, sozinha, não dá conta de tudo isso. A noção de Discurso, então, tem a ver com ser um tipo de pessoa. É por esse motivo que podemos dizer que:

Um Discurso com ' $D$ ' maiúsculo é composto de modos distintos de falar/ouvir e muitas vezes também de escrever/ler, juntamente com formas distintas de agir, interagir, valorizar, sentir, vestir, pensar, crer, com outras pessoas e com vários objetos, ferramentas e tecnologias, de modo a representar identidades socialmente reconhecíveis. (2011, p. 37). ${ }^{7}$

Como se pode ver, a noção de Discurso é mais ampla, pois envolve questões de representação e reconhecimento; significa que, além da língua, outras coisas estão envolvidas. Dessa forma, um conceito não exclui ou se opõe ao outro, pois a noção de discurso é abarcada pela de Discurso. Falamos e agimos não apenas como indivíduos, mas como membros de grupos sociais

\footnotetext{
${ }^{4}$ No original: "to support the performance of social activities and social identities and to support human affiliation within cultures, social groups, and institutions.".

${ }^{5}$ No original: “[...] language and institutions 'bootstrap' each other into existence in a reciprocal process through time.”.

${ }^{6}$ Abordaremos melhor a questão das identidades mais adiante, mas, por enquanto, podemos entendê-las como "[...] diferentes formas de participar de diferentes tipos de grupos sociais, culturas e instituições"/ "[...] different ways of participating in different sorts of social groups, cultures, and institutions”. (GEE, 2005, p. 1).

${ }^{7}$ No original: “A Discourse with a capital ' $\mathrm{D}$ ' is composed of distinctive ways of speaking/listening and often, too, writing/reading coupled with distinctive ways of acting, interacting, valuing, feeling, dressing, thinking, believing, with other people and with various objects, tools, and technologies, so as to enact specific socially recognizable identities.".
} 
e culturais, que são muitos e diversos. Ou seja, falamos sempre como membros de Discursos determinados. Compartilhamos com cada um desses grupos convenções sobre os modos de usar a língua, já que cada um deles tem uma maneira distinta de associar as palavras às identidades e atividades. Normalmente, ao nascermos, tais grupos já existem, antes da nossa própria existência, bem como continuarão existindo após morrermos. Isto é, tais grupos continuam existindo através do tempo e da história, e nós somos seus “porta-vozes temporários”. (GEE, 2005; 2011).

Somos membros de muitos Discursos ao mesmo tempo, e eles influenciam uns aos outros, muitas vezes se misturando e criando novos Discursos a partir de um processo de hibridização. Assim sendo, quando qualquer um de nós assume determinado tipo cultural específico de pessoa cotidiana (um determinado tipo de professor, por exemplo), usamos a língua, outras formas de significação, bem como assumimos formas de agir, interagir, sentir, acreditar e valorizar específicas para reconhecermos a nós mesmos e aos outros. Através desse processo, produzimos, reproduzimos, sustentamos e até mesmo transformamos determinados Discursos.

A princípio, como forma de marcar a distinção existente entre discurso e Discurso, Gee (2005) fala em uma análise de D/discurso, demonstrando que não pensa, durante a análise, apenas na língua, embora ela seja muito importante. Após apresentar seus argumentos sobre essa distinção de forma clara, os quais já trouxemos aqui, o autor decide adotar "análise do discurso" para fazer referência aos dois termos, o que também será feito por nós por ser mais didático.

Essa maneira de definir Discurso mostra que, necessariamente, ele se distingue da noção de língua, e principalmente da língua fora do uso. O que o autor (1996) considera importante não é saber apenas a gramática da língua, mas o seu uso. É por isso que Gee (2005, p. 8, grifos do autor) considera que a teoria central da análise do discurso por ele desenvolvida é: "a língua só tem significado em e através de práticas sociais"8. Como já vimos, não é apenas a língua que compõe um Discurso, o que implica no fato de que não apenas o modo como se usa a língua é relevante, “[...] mas quem você é e o que você está fazendo quando você diz isso.”. 9 (GEE, 1996, p. 124, grifos do autor). Discursos têm, necessariamente, relação com os usos da língua e são historicamente constituídos. É exatamente por isso que eles estão sempre relacionados ao contexto, que é um elemento essencial. Conforme Gee (1996, p. 149):

Um texto é significativo somente dentro do padrão (ou configuração social) que ele forma em um momento e lugar específicos com outras peças de linguagem, bem como com pensamentos específicos, palavras, atos, corpos, ferramentas e objetos. E esse padrão ou configuração - esta ação social específica - é ela mesma

\footnotetext{
${ }^{8}$ No original: "language has meaning only in and through social practices".

${ }^{9}$ No original: "[...] but who you are and what you're doing when you say it.".
} 
significativa somente dentro de um Discurso específico ou na interseção de diversos Discursos. ${ }^{10}$

Gee (1996) define dois tipos amplos de Discursos na sociedade: os primários e os secundários. Aqueles estão relacionados aos nossos processos de socialização primários, quais sejam, os familiares. Nossa primeira identidade social se constitui a partir deles, e é com base neles que estabelecermos relação com todos os outros Discursos - secundários -, aceitando-os ou recusando-os. Nossas crenças e valores são constituídos, primeiramente, a partir deles. Já os Discursos secundários são aqueles que aprendemos em nossa socialização fora do âmbito familiar, seja em instituições ou outros grupos sociais (escola, igreja, trabalho, dentre outros). A separação entre esses dois tipos, no entanto, não é assim tão simples, pois os limites entre eles muitas vezes não são tão claros, já que as pessoas podem usar aspectos de seus Discursos primários ao desempenhar atividades e assumir uma posição dentro de algum de seus Discursos secundários. Do mesmo modo, os Discursos secundários que vão sendo adquiridos por uma pessoa podem mudar a forma como se relaciona com seu Discurso primário, alterando-o. Isso tem a ver com o fato de que os Discursos podem passar por processos de hibridização e, dessa forma, vão se influenciando mutuamente e sofrendo alterações ao longo da história. Isso ocorre porque eles não são unidades com limites claramente definidos. Sendo assim, as pessoas, ao longo da história, sempre criam novos Discursos, contestando os limites de cada um, que vai mudando sempre que um deles surge ou morre.

A partir da noção de que participamos, ao mesmo tempo, de vários Discursos, e que por isso somos múltiplos, podemos perceber que os Discursos nos quais estamos inseridos podem ser conflitantes entre si. Esses conflitos demonstram que os próprios indivíduos, por desenvolverem práticas com base em seus Discursos, podem enfrentar conflitos reais no que diz respeito aos seus valores e identidades (GEE, 2005). Isso fica expresso de forma mais clara quando Gee (1996, p. ix) explica que:

Cada um de nós é membro de muitos Discursos, e cada Discurso representa uma de nossas múltiplas identidades. Esses Discursos não precisam - e geralmente não o fazem - representar valores consistentes e compatíveis. Existem conflitos entre eles, e cada um de nós vive e respira esses conflitos enquanto atuamos nossos

\footnotetext{
${ }^{10}$ No original: "A text is meaningful only within the pattern (or social configuration) it forms at a specific time and place with other pieces of language, as well as with specific thoughts, words, deeds, bodies, tools, and objects. And this pattern or configuration - this specific social action - is itself meaningful only within a specific Discourse or at the intersection of several Discourses."
} 
vários Discursos. Para alguns, esses conflitos são mais dramáticos do que para outros. [...] Eles são o local de luta e resistência muito real. ${ }^{11}$

Falar em Discurso primário e secundário nos remete às noções definidas por Gee (1996) como "aquisição" e "aprendizagem". Enquanto a aquisição significa adquirir algo com base em tentativas e erros, através da exposição a modelos e da prática dentro de um grupo social, sem acesso a um ensino formal, o aprendizado:

[...] é um processo que envolve conhecimento consciente adquirido através do ensino (embora não necessariamente de alguém designado oficialmente como professor) ou através de certas experiências de vida que desencadeiam reflexão consciente. Esse ensinamento ou reflexão envolve explicação e análise, isto é, quebrando a coisa a ser aprendida em suas partes analíticas. Inerentemente envolve alcançar, junto com a matéria ensinada, algum grau de meta-conhecimento sobre ela. ${ }^{12}$ (GEE, 1996, p. 138).

Para Gee (1996), desempenhamos melhor aquilo que adquirimos, mas conscientemente sabemos mais aquilo que aprendemos. Muito do que aprendemos depois de nossos primeiros processos de socialização, no entanto, envolve uma mistura entre aquisição e aprendizado. Consideramos essencial, baseados nas ideias colocadas pelo autor, um equilíbrio entre esses dois processos, pois a ausência de aquisição leva a pouco domínio na prática, mas a falta de aprendizado tem como consequência pouca consciência crítica e analítica. Mas a importância desse equilíbrio não exclui a necessidade de que a aquisição, em certa medida, sempre preceda o aprendizado. Discursos não podem ser apreendidos a partir do aprendizado, mas somente a partir da aquisição, e isso se dá apenas a partir do contato com as práticas sociais desenvolvidas nesse Discurso.

A necessidade de que a aquisição venha antes pode ser mais bem compreendida se pensarmos sobre a seguinte questão colocada por Gee (1996): um Discurso ao qual pertencemos não poderia trabalhar se, após o adquirirmos, tivéssemos consciência disso e pensássemos a todo instante sobre o que fazemos estando inseridos nesse Discurso. A partir do momento em que dominamos algo, não temos muita consciência desse fato, e é isso que nos permite agir. Ao contrário, quando nos deparamos com uma situação à qual não conseguimos nos adaptar, estamos a

\footnotetext{
${ }^{11}$ No original: "Each of us is a member of many Discourses, and each Discourse represents one of our ever-multiple identities. These Discourses need not, and often do not, represent consistent and compatible values. There are conflicts among them, and each of us lives and breathes these conflicts as we act out our various Discourses. For some, these conflicts are more dramatic than for others. [...] They are the site of very real struggle and resistance."

${ }^{12}$ No original: "[...] is a process that involves conscious knowledge gained through teaching (though not necessarily from someone officially designated a teacher) or through certain life-experiences that trigger conscious reflection. This teaching or reflection involves explanation and analysis, that is, breaking down the thing to be learned into its analytic parts. It inherently involves attaining, along with the matter being taught, some degree of meta-knowledge about the matter."
} 
todo instante conscientes sobre o que estamos fazendo, ou mesmo sobre o que somos chamados a fazer por ocupar determinada posição.

Se, ao adquirirmos um conhecimento, conseguimos concomitantemente desenvolver metaconhecimentos sobre a questão em foco, podemos equilibrar as duas dimensões. Isso ocorre, na maioria das vezes, de forma inconsciente e nos possibilita refletir sobre a prática, o que torna possível, inclusive, mudá-la, caso se considere necessário. Se gastamos nosso tempo apenas com o aprendizado e deixamos de lado a aquisição, não estamos nos preparando para o desempenho desse conhecimento. Por outro lado, o aprendizado também é essencial, porque é esse meta-conhecimento que nos leva à reflexão e possíveis críticas, as quais podem levar à mudança. E uma crítica a um Discurso precisa partir sempre de dentro dele próprio. Não se pode tomar um Discurso como parâmetro para crítica de outro. Afinal, eles são o próprio limite do entendimento que uma pessoa tem a respeito das questões que a cercam.

A língua não tem significado fora do uso, mas a partir do momento em que o falante a toma para si e utiliza os recursos de sua gramática para construir textos, ela é dotada de um caráter político, pois demonstra uma visão particular sobre o mundo: sobre aquilo que é normal ou não, aceito ou não, certo ou não, possível ou não, dentre tantos outros aspectos que estão em jogo quando assumimos pontos de vista a partir do uso da língua. Os textos são formas de construir e expressar perspectivas sobre o mundo, de realizar atividades e estabelecer identidades sociais diversas. Tais perspectivas influenciam na maneira como cada um de nós desejamos que os bens sociais sejam distribuídos. Enfim, essas perspectivas influenciam no modo como agimos em relação a tais crenças e desejos (GEE, 2005). Logo, a política, que aqui nada tem a ver com partidos políticos, mas sim com a distribuição de bens sociais, "é parte e parcela do uso da língua". ${ }^{13}$ (GEE, 2005, p. 2).

A partir disso conseguimos entender por que, para Gee (1996), o papel e a importância da Análise do Discurso estão diretamente relacionados à função das ideologias. Elas são vistas por ele como uma “[...] teoria social que envolve generalizações (crenças, reivindicações) sobre a(s) forma(s) como os bens são distribuídos na sociedade"14 (1996, p. 21), sendo que esses bens são definidos como "[...] qualquer coisa que as pessoas na sociedade em geral acreditam ser benéfico ter ou prejudicial não ter, quer se trate da vida, espaço, tempo, 'boas' escolas, 'bons' empregos, riqueza, status, poder, controle, ou o que quer que seja” (1996, p. 21) $)^{15}$. Gee (1996) considera que

\footnotetext{
${ }^{13}$ No original: "Politics is part and parcel of using language".

${ }^{14}$ No original: "[...] a social theory which involves generalizations (beliefs, claims) about the way (s) in which goods are distributed in society.".

${ }^{15}$ No original: "[...] anything that the people in the society generally believe are beneficial to have or harmful not to have, whether this be life, space, time, 'good' schools, 'good' jobs, wealth, status, power, control, or whatever".
} 
as ideologias são importantes porque elas criam, juntamente com a história e as bases materiais da sociedade, o mundo, as realidades humanas, bem como o próprio homem, pois o que o constitui são “bens” cuja distribuição é controlada pela ideologia.

Na medida em que as ideologias são tácitas, ocultas, somos guiados por elas, ainda que isso ocorra, na maioria das vezes, de forma inconsciente. Entretanto, através de nossas práticas sociais é possível identificá-las. Nisso consiste, para o autor (1996), o papel da Análise do Discurso: ao percebermos, a partir da observação de nossas práticas, que nossos discursos/ações são prejudiciais aos outros ou a nós mesmos, torna-se necessária uma atividade reflexiva sobre nossas escolhas. Nesse sentido, a Análise do Discurso acaba se mostrando como uma questão ética. Isso tem também a ver com o fato de algumas abordagens de Análise do Discurso, incluindo a de Gee, serem chamadas de críticas. Por assumirem, em suas análises, o caráter político da língua em uso, consideram que:

[...] a língua em uso é sempre parte e parcela de, e sempre parcialmente constitutiva de práticas sociais específicas, e que essas práticas sociais sempre têm implicações para coisas inerentemente políticas, com status, solidariedade, a distribuição de bens sociais e poder. ${ }^{16}$ (GEE, 2011, p. 28).

\section{Contexto e Modelos Discursivos}

Os contextos são centrais nesta teoria e estão diretamente relacionados à noção de discurso. Eles incluem conjunto de pessoas, de objetos e locais, definem os significados, os quais estão no uso das palavras, e não nelas propriamente ditas. O contexto determina, inclusive, os nossos papéis, as várias identidades que assumimos. Como nos mostra Gee (1996, p. 66, grifo do autor):

Em primeiro lugar, somos todos, apesar de nossas ilusões comuns sobre o assunto, não um único quem, mas várias, diferentes pessoas em diferentes contextos. Em segundo lugar, um mesmo falar e um mesmo agir podem ter valores diferentes em contextos diferentes. Realizamos diferentes "quem" e "o que" através do uso de diferentes linguagens sociais. ${ }^{17}$

Para Gee (1996, p. 77-78), “O contexto tem o desagradável hábito de quase sempre parecer claro, transparente, não problemático, quando ele, na verdade, quase nunca é". ${ }^{18}$ Ele também não é

\footnotetext{
${ }^{16}$ No original: “[...] language-in-use is always part and parcel of, and partially constitutive of, specific social practices, and that social practices always have implications for inherently political things like status, solidarity, the distribution of social goods, and power.".

${ }^{17}$ No original: "First, we are all, despite our common illusions about the matter, not a single who, but a great many, different whos in different contexts. Second, one and the same speaking or acting can count as different things in different contexts. We accomplish different whos and whats through using different social languages."

${ }^{18}$ No original: "Context has the nasty habit of almost always seeming clear, transparente, and unproblematic, when it hardly ever actually is.”.
} 
algo visível enquanto falamos, mas algo que as pessoas fazem suposições sobre e, a partir dessas suposições, agem e falam buscando adequar-se. Isto é,

Elas assumem que tanta coisa do que foi dito (ou escrito) anteriormente é relevante para o que está sendo dito agora; elas assumem que tanta coisa da configuração física é relevante para o que está sendo feito agora; elas assumem que o falante acredita de uma tal maneira e em tais valores. ${ }^{19}$ (GEE, 1996, p. 75).

Isso tem a ver com o que dissemos anteriormente sobre o fato de que, ao mesmo tempo em que buscamos adequar o que dissemos à situação, somos nós que a criamos. De acordo com a perspectiva apresentada, portanto, não cabe pensar o contexto como acréscimo ou pano de fundo, mas como parte constitutiva e, por isso, essencial. Isso pode ser percebido, por exemplo, na diferenciação que o autor (2004) estabelece entre um significado que é mais geral e o significado situado. Cada palavra tem um significado potencial, que é um significado mais estabilizado. Contudo, existe um nível mais específico de significação da palavra, em que é necessário ter em mente o contexto de uso para determinar o que ela significa naquele determinado momento. Para o autor (2011), este último envolve um problema bem mais profundo, o da moldura, que é tanto um problema quanto uma ferramenta. É problema no sentido de que nossas análises discursivas estão sempre sujeitas à mudança de acordo com o contexto. Ao mesmo tempo, é ferramenta, porque é possível ampliar o contexto e analisar quais valores e informações deixam de ser ditos quando se usa determinada peça de linguagem e não outra, o que tem relação com as escolhas feitas pelo falante e o modo como elas interferem nos significados daquilo que dizemos.

Tais significados não estão associados exclusivamente aos contextos. Eles dependem também das próprias escolhas que fazemos, ou seja, dentre as palavras que podemos usar para dizer algo, qual delas escolhemos; o que é um processo, na maioria das vezes, inconsciente. Como nos diz Gee (1996, p. 76), "Palavras não têm significado nelas mesmas e por elas à parte de outras palavras. Elas têm significados somente relativos às escolhas (pelos falantes ou escritores) e suposições (pelos ouvintes ou leitores) sobre outras palavras e sobre contextos." ${ }^{20}$. Conscientes ou não, fazemos escolhas a todo instante, e elas são importantes porque podem significar a exclusão de outra possibilidade de uso. Gee (2005, p. 46, grifo do autor) ${ }^{21}$ expressa a relação entre os significados e os contextos de uma forma bastante clara quando diz que “[...] significado não é

\footnotetext{
${ }^{19}$ No original: "They assume that just so much of the preceding speech (or writing) is relevant to what is being said now; they assume that just so much of the available physical setting is relevant to what is being said; they assume that the speaker believes so and so and has such and such values.".

${ }^{20}$ No original: "Words have no meaning in and of themselves and by themselves apart from other words. They have meanings only relative to choices (by speakers and writers) and guesses (by hearers and readers) about other words, and assumptions about contexts.".

${ }^{21}$ Para o desenvolvimento dessa asserção, Gee toma como base o texto "Relevance: Communication and Cognition" (1986), de Sperber e Wilson.
} 
meramente uma questão de decodificar a gramática, é também (e mais importante) uma questão de saber quais das muitas inferências que uma pessoa pode extrair de um enunciado são relevantes.". 22 E a relevância está totalmente relacionada ao contexto, ao ponto de vista e à cultura.

As escolhas e suposições que fazemos, chamadas por Gee (1996) de "distinções significativas", são feitas sempre com base em crenças e valores, os quais são vistos como teorias sociais que "[...] envolvem (geralmente de forma inconsciente) suposições sobre modelos de mundos simplificados"23 (GEE, 1996, p. 78), os denominados modelos Discursivos, que são:

[...] vídeos ou fitas de vídeo na mente. Todos nós temos um vasto estoque desses vídeos, cada um dos quais descreve eventos prototípicos (o que tomamos como 'normal') em um mundo simplificado. Convencionalmente, tomamos esses mundos simplificados para serem o mundo 'real' ou atuar como se fossem. Fazemos nossas escolhas e suposições sobre o significado em relação a esses mundos.

Esses modelos culturais são visões emblemáticas de uma realidade idealizada, 'normal', 'típica' [...] Eles são também variáveis, diferindo através dos diferentes grupos culturais, incluindo diferentes grupos culturais em uma sociedade falante da mesma língua. Eles mudam com o tempo e outras mudanças na sociedade, mas geralmente somos bastante inconscientes de que os estamos usando e de suas implicações. (GEE, 1996, p. 78). ${ }^{24}$

No trecho acima, podemos ver que o autor se refere a tais teorias como "modelos culturais". Entretanto, ele (2005) reformula esse conceito e passa a falar em modelos Discursivos, por considerar que o primeiro termo não é tão adequado. Esse nome é dado pelo fato de serem teorias que estão enraizadas em práticas de grupos sócio-culturalmente definidos. Entretanto, “Nem todo mundo que compartilha um determinado modelo é membro de todas as mesmas culturas e nem todos, em alguma cultura maior, compartilham todos os mesmos modelos." 25 (GEE, 2005, p. 61). Assim sendo, falar em "modelos Discursivos" parece mais adequado, já que essas teorias estão sempre conectadas a Discursos específicos.

Os modelos Discursivos fazem parte do funcionamento de qualquer língua, bem como da construção de realidades, sendo impossível integrar grupos sociais e conhecer uma língua sem conhecer seus modelos Discursivos. (GEE, 1996). Eles são carregados de valores, de perspectivas,

\footnotetext{
${ }^{22}$ No original: “[...] meaning is not merely a matter of decoding gramar, it is also (and more importantly) a matter of knowing which of the many inferences that one can draw from an utterance are relevant."

${ }^{23}$ No original: "[...] involve (usually unconscious) assumptions about models of simplified worlds.".

${ }^{24}$ No original: "[...] movies or videotapes in the mind. We all have a vast store of these tapes, each of which depicts prototypical (what we take to be 'normal') events in a simplified world. We conventionally take these simplified worlds to be the 'real' world, or act as if they were. We make our choices and guesses about meaning in relation to these worlds. These cultural models are emblematic visions of an idealized, 'normal', 'typical' reality [...] They are also variable, differing across different cultural groups, including different cultural groups in a society speaking the same language. They change with time and other changes in the society, but we are usually quite unaware we are using them and of their full implications.".

${ }^{25}$ No original: "Not everyone who shares a given model is a member of all the same cultures and not everyone in some larger culture shares all the same models."
} 
de forma que o conteúdo de um pode ser conflitante em relação a outros. É justamente por isso que “[...] todos os modelos culturais tendem, em última análise, a limitar nossa percepção das diferenças e das novas possibilidades. Eles nos permitem funcionar no mundo com facilidade, mas ao preço de estereótipos e de pensamento e percepção rotineiros." (GEE, 1996, p. 89). ${ }^{26}$ Certas exclusões, então, são ocasionadas pelos modelos Discursivos. É a partir deles que damos sentido aos textos e ao próprio mundo. Eles definem, por exemplo, o que é tido como central, típico e o que é marginal, atípico. É por isso que desempenham um papel na criação e manutenção de estereótipos.

Como já dissemos, essas teorias são compartilhadas em um grupo social, pois têm suas raízes em práticas de grupos sociais. Diferentes grupos sociais e culturais possuem teorias diferentes sobre cada coisa no mundo. Tomemos como exemplo a categoria profissional "professor": de acordo com os grupos aos quais pertence uma pessoa, um determinado modelo sobre a função do professor permitirá que ela atribua sentido às ações de professores, por exemplo. Caso ela seja um professor, a maneira como percebe a função docente direcionará suas ações. Assim, diferentes identidades sociais serão assumidas, as quais serão reconhecidas a partir de linguagens sociais específicas.

Alguns modelos Discursivos são compartilhados entre vários Discursos diferentes, enquanto outros estão restritos a apenas um Discurso, ou a um número reduzido deles. Como nos mostra Gee (2005, p. 62), “[...] os significados situados das palavras são conectados a diferentes modelos Discursivos, ligados a grupos sociais específicos e seus Discursos característicos". ${ }^{27}$ Ao contrário do que possa parecer, os modelos Discursivos existem tanto nas nossas práticas sociais quanto em nossas cabeças. Eles são compartilhados entre as próprias pessoas, pela mídia, pelos livros e várias outras práticas sociais. É a partir desses modelos Discursivos que fazemos nossas escolhas, que atribuímos sentidos ao mundo e agimos. É com base neles que se dão as nossas práticas sociais. Nesse sentido, nossa mente é social, porque nossos modelos Discursivos, enraizados em nossas práticas culturais, guiam nossas ações, nosso modo de pensar, atribuir valores e interagir. Qualquer modelo Discursivo está ligado a uma espécie de simulação que criamos em nossa mente. Essas simulações nos ajudam tanto a pensar sobre o mundo, quanto a nos preparar para agirmos nele. Elas nunca são neutras, mas sempre baseadas em uma perspectiva ou outra, que são definidas com base em nossas experiências e em nossos Discursos. (GEE, 2005).

\footnotetext{
${ }^{26}$ No original: “[...] all cultural models tend ultimately to limit our perception of differences and of new possibilities. They allow us to function in the world with ease, but at the price of stereotypes and routinized thought and perception."

${ }^{27}$ No original: "[...] the situated meanings of words are connected to different Discourse models linked to specific social groups and their characteristics Discourses."
} 
É importante ressaltar que nenhum modelo Discursivo é completo ou consistente, pois cada um deles incorpora valores sociais e discursivos diferentes e conflitantes entre si; há ainda casos em que os valores incorporados em um modelo servem mais aos interesses de outras pessoas, as quais não compartilham aquele modelo, do que aos de quem de fato compartilha. Assim, muitas vezes é difícil saber, por exemplo, se uma pessoa detém dois modelos Discursivos conflitantes ou se apenas um modelo heterogêneo, conflituoso. Para Gee (2005, p. 85), essa inconsistência dos modelos Discursivos é reflexo dos conflitos que nós vivemos: "Mas, em última análise, a parcialidade e inconsistência dos modelos de Discurso reflete o fato de que todos nós tivemos muitas e diversas experiências conflitantes; todos nós pertencemos a grupos diferentes, às vezes conflitantes [...]". ${ }^{28}$ A esse respeito, alguns questionamentos são pertinentes quando se desenvolve uma análise: quais modelos Discursivos são relevantes naquele recorte analisado? Como eles ajudam a reproduzir, transformar ou até mesmo criar relações sociais, culturais e políticas? Esses modelos Discursivos estão criando, transformando ou reproduzindo quais Discursos? Quais textos, mídias, experiências, interações e instituições podem ter dado origem aos modelos Discursivos identificados?

A língua em uso - discurso - executa ações no mundo. Assim, Gee (2011) mostra como ela pode ser usada não apenas para dizer algo, mas também para construir coisas no mundo com a ajuda de ferramentas não-verbais. A partir disso, o autor $(2005,2011)$ define sete tarefas de construção da língua, sendo que realizar uma análise discursiva envolve fazer questionamentos sobre essas sete tarefas, com a ajuda das ferramentas de investigação propostas pelo autor, tais como os significados situados, linguagens sociais, modelos Discursivos, intertextualidade, Discursos e Conversações, ou mesmo considerar qualquer aspecto da língua que pareça relevante no material analisado

É possível, a partir da língua, construir diversos aspectos de nossa vida social, os quais serão elencados a seguir:

(1) podemos construir significados para as coisas, pois eles são dados de antemão, mas atribuídos por nós;

(2) também "Usamos a língua para sermos reconhecidos como engajados em certo tipo de atividade, isto é, para construir uma atividade aqui-e-agora." ${ }^{29}$ (GEE, 2005, p. 11); (3) também construímos identidades, as quais têm relação com ser reconhecido como alguém que assume determinado papel;

\footnotetext{
${ }^{28}$ No original: "But ultimately, the partiality and inconsistency of Discourse models reflects the fact that we have all had a great many diverse and conflicting experiences; we all belong to different, sometimes conflicting groups [...]".

${ }^{29}$ No original: "We use language to get recognized as engaging in a certain sort of activity, that is, to build an activity here-and-now."
} 
(4) construímos e sustentamos através da língua relações com outras pessoas, com grupos e instituições;

(5) a política, vista como situações em que a distribuição de qualquer bem social está em jogo, também é construída através do uso da língua;

(6) precisamos mencionar ainda que as coisas no mundo podem ser relacionadas entre si (ou não) de muitas maneiras, e isso se dá a partir do uso que fazemos da língua. Gee (2005) cita como exemplo a conexão existente entre malária e pobreza. Podemos fazer com que tais conexões estejam ou não visíveis em nossa linguagem;

(7) construímos, por fim, privilégios (ou não) para determinados sistemas de signos e conhecimento. Há várias formas de conhecer o mundo e vários sistemas de comunicação. Através do uso que fazemos da língua, podemos dar destaque a um ou outro sistema de signos, atribuir prestígio a uma forma de conhecimento sobre outras.

\section{A NOÇÃO DE IDENTIDADE EM GEE}

Dentre as tarefas de construção da língua, daremos ênfase, aqui, à identidade. Tal noção, na percepção do autor, tem a ver com ser reconhecido como um tipo de pessoa em determinado contexto. Uma mesma pessoa tem múltiplas identidades, as quais são dinâmicas e estão relacionadas às suas performances na sociedade, e não a um estado interno. $\mathrm{O}$ autor aponta quatro perspectivas a partir das quais as identidades podem ser pensadas, sendo que elas não estão separadas. Ainda assim, é possível pensar se em determinado contexto uma perspectiva pode predominar em relação às outras, buscando entender o motivo por que isso ocorre.

Uma primeira perspectiva para se pensar a noção de identidade é a questão natural, alguma característica biológica que seja importante na identificação de uma determinada pessoa. A fonte dessa característica é a natureza, mas ela pode ser sustentada, por exemplo, por uma instituição ou pela participação em um grupo de afinidade. Isso porque qualquer identidade precisa ser sustentada, e para tal ela precisa ser reconhecida, ou por outras pessoas, ou pela própria pessoa que a assume.

Uma segunda perspectiva é a identidade institucional, a qual tem relação com a posição social que um indivíduo ocupa, que depende da forma como ele é reconhecido socialmente. Conforme Gee (2000), junto com a posição vão direitos e responsabilidades, e por trás dela estão regras, estatutos e tudo aquilo que institucionalmente permite que as autoridades criem determinada posição/identidade e que determina a maneira pela qual aquele que ocupa essa posição age diante do papel social a que está vinculado. Visto que a origem dessa posição é um conjunto de autoridades institucionais, muitas vezes essa identidade pode ser vista por algumas pessoas como 
algo que é imposto; é importante observar, então, se uma determinada posição institucional é ocupada mais passivamente ou mais ativamente.

Um terceiro modo de se pensar a identidade é a partir dos discursos. Trata-se, então, da identidade discursiva, a qual depende sempre do reconhecimento do outro para ser estabelecida. Tal reconhecimento só acontece por meio do diálogo estabelecido entre as pessoas. (GEE, 2005). Essa identidade discursiva, portanto, está relacionada a características individuais, mas que não são construídas pela própria pessoa, pois depende do discurso do outro para ser sustentada. Embora o discurso seja o foco na construção da identidade discursiva, ele exerce papel fundamental no estabelecimento das identidades de outros tipos, tal como no caso da institucional. Uma instituição precisa de discursos que sustentem as identidades institucionais, por exemplo.

Outra maneira de se pensar a respeito da identidade é a partir da noção de afinidade. É possível, com base nos interesses de determinada pessoa, que se crie afinidade com determinado(s) grupo(s) e, a partir da ideia de pertencimento, assumir um papel específico na sociedade; logo, criar uma identidade. Novamente, notamos como o discurso funciona e sustenta não apenas identidades discursivas, já que, embora sejam práticas específicas que sustentem essas identidades, é possível que seja desenvolvido um discurso próprio nessas práticas.

Como já vimos, todas essas perspectivas estão relacionadas, mas as identidades sempre podem ser negociadas, aceitas ou não, no sentido de contestar qual a perspectiva predominante a partir da qual elas são vistas, reconhecidas. As combinações a partir das quais alguém vai ser reconhecido como certo tipo de pessoa sempre fazem parte de um Discurso. Toda pessoa tem experiências, tem uma trajetória dentro de um espaço Discursivo, ou ainda, toda pessoa tem experiências específicas dentro de Discursos específicos. Essas experiências que constituem sua trajetória em um Discurso e a maneira como a própria pessoa as narra são essenciais para a definição de uma quinta perspectiva sobre a identidade, que é o que Gee (2000) chama de “identidade central". Assim como nas outras perspectivas, a identidade central nunca está completamente formada, mas sim em constante mudança. O que é diferente aqui é a perspectiva a partir da qual se observa: a fonte da identidade não é mais o reconhecimento de outras pessoas, ou instituição, por exemplo, mas o Discurso da própria pessoa, com base em suas experiências. A experiência, assim, é peça fundamental quando se analisa a identidade sob essa perspectiva, pois “Os Discursos são sociais e históricos, mas a trajetória da pessoa e sua narrativização são individuais (embora seja uma individualidade completamente formada e informada socialmente)." ${ }^{\prime 30}$ (GEE, 2000, p. 24).

\footnotetext{
${ }^{30}$ No original: "The Discourse are social and historical, but the person's trajectory and narrativization is individual (though an individuality that is fully socially formed and informed)."
} 
Identidades de qualquer tipo precisam ser reconhecidas a partir de um sistema de signos. Logo, a língua faz parte do processo de funcionamento das identidades, mas não está sozinha nele, pois precisa ser vista dentro do contexto do Discurso, e a noção de Discurso, como já vimos, envolve muito mais do que apenas a língua. Além disso, mais do que a língua propriamente dita, é importante analisar o que Gee (1996, 2005, 2011) chama de linguagem social. Para esse autor, as pessoas não falam uma língua "em geral”, mas sempre uma variedade específica da língua, e diferentes variedades em diferentes contextos. Isso diz respeito ao conceito de linguagens sociais, que pode ser definido como "[...] diferentes variedades da língua que permitem a nós expressar diferentes identidades socialmente significativas [...] e estabelecer diferentes atividades socialmente significativas." ${ }^{31}$ (GEE, 2005, p. 35). Observar a linguagem social é observar, portanto, quem e quais atividades estão sendo comunicadas através da língua, ou seja, qual a "voz" que está falando, quem está falando, e o que essa pessoa está tentando fazer. Gee (2005) mostra que, apesar de próximos, os conceitos de Discurso e de linguagem social não fazem referência a uma mesma questão, já que esta é usada para dizer do papel desempenhado pela língua nos Discursos. Diferentes linguagens sociais relevam diferentes identidades, já que aquelas são uma combinação entre 'who-doing-what', ou seja, alguém desempenhando alguma atividade. E essas possibilidades de "quem" e "o que" são criadas e modificadas historicamente, e não algo que a própria pessoa define, pois, como já vimos, ninguém está fora de Discurso(s), mas sim inserido em vários, os quais influenciam diretamente nossas ações.

Nem todos os professores, por exemplo, falam da mesma forma. Há, então, subvariedades dentro de cada categoria mais ampla. O que importa, no entanto, não é o nome que se dá a uma linguagem social, mas que a partir dela seja possível reconhecer quem está falando, ou seja, qual identidade social está sendo assumida. Isso demonstra que, mesmo sendo parte de um mesmo grupo (de professores, por exemplo), não é possível pensar em uma homogeneidade, pois a identidade de professor pode estar associada a diferentes linguagens sociais. Além do mais, já dissemos que a experiência, que é sempre individual, é essencial na definição de qualquer identidade central. Sendo individual, é fator de diferenciação entre indivíduos, mesmo que pertençam a um mesmo Discurso. Considerando que os Discursos primários influenciam na maneira como os Discursos secundários são recebidos por alguém e que uma mesma pessoa está inserida em vários Discursos, é possível que um professor, por exemplo, compartilhe com outro apenas um Discurso, e não outros. Assim, esses professores possivelmente terão modelos Discursivos diferentes a respeito de uma mesma questão, o que não permite pensar em uma padronização de um grupo social.

\footnotetext{
${ }^{31}$ No original: "[...] different varieties of language that allows us to express different socially significant identities [...] and enact different socially meaningful activities".
} 
Ao falar em diferentes formas de posicionamento em relação a uma mesma questão, é importante colocar em cena um importante conceito proposto por Gee (2005), o de Conversações, que são:

[...] debates na sociedade ou dentro de grupos sociais específicos (sobre questões de destaque tais como tabagismo, aborto ou a reforma escolar) que um grande número de pessoas reconhece, tanto em termos de 'lados' a serem tomados nesse debates, quanto quais tipos de pessoas tender a estar em cada lado." ${ }^{32}$ (GEE, 2005, p. 35).

As Conversações são sempre compostas de eventos interacionais que se dão entre pessoas específicas em um momento e lugar determinados. Valores e crenças desempenham papel importante nas Conversações, e os temas e valores que compõem cada uma delas circulam em vários textos e na mídia; circulam nos Discursos. Aliás, esse conceito está completamente relacionado à noção de Discurso, dependendo deles para surgir, pois os temas e valores de uma Conversação "[...] são os produtos das disputas históricas entre diferentes Discursos". ${ }^{33}$ (GEE, 2005, p. 50). Isso não significa, porém, que as pessoas obrigatoriamente saibam sobre os eventos que contribuíram para criar ou sustentar esses valores e temas em uma determinada época e que permitiram que eles chegassem até os dias atuais. Muitas vezes elas conhecem esses temas e valores, mas desconhecem seu percurso histórico. O que cria as Conversações então, isto é, esses debates, são as interações entre Discursos.

Baseados em Gee (1996, 2005, 2011), entendemos que interessa na análise verificar não apenas o que é dito, mas também o modo como se diz. Mais que isso, interessa saber qual identidade se assume no momento em que se diz. É preciso que haja uma combinação entre palavraação-valor reconhecida e aceita por outras pessoas em determinado contexto para que se possa assumir determinada identidade. Sem esse reconhecimento, não é possível assumir identidade alguma. Ou seja, é preciso ser reconhecido como alguém que faz parte de um Discurso específico, isto é, como uma forma determinada de ser no mundo, alguém-fazendo-alguma coisa específica.

Não há homogeneização dentro de um grupo, já que diferentes linguagens sociais podem ser usadas, as quais estão relacionadas a diferentes modelos Discursivos e estabelecem diferentes identidades, associadas a diferentes Discursos. (GEE, 1996). Conforme Gee (2005), o que é ser determinado tipo de pessoa e as atividades a ela atreladas vão sendo estabelecidos provisoriamente

\footnotetext{
${ }^{32}$ No original: "[...] debates in society or within specific social groups (over focused issues such as smoking, abortion, or school reform) that large numbers of people recognize, in terms of both what 'sides' there are to take in such debates and what sorts of people tend to be on each side."

${ }^{33}$ No original: "[...] are the products of historical disputes between and among different Discourses".
} 
e continuamente, isto é, vão sendo definidos pela prática e também são modificados por ela, que é sempre definida historicamente.

\section{ALGUMAS CONSIDERAÇÕES}

Este trabalho permite ver que a teoria proposta por Gee, tal como as outras vertentes de Análise do Discurso, possibilitam entender a sociedade de um modo geral, as relações nela estabelecidas, as questões de poder que a perpassam. Contudo, sabemos que cada autor enfatiza, de acordo com os seus interesses e preocupações, um ou mais pontos específicos da cultura, seja a religião, a política, dentre tantos outros campos constituintes da sociedade. O próprio Gee destaca a relevância de suas proposições para o universo escolar, já que a educação é campo de maior interesse do autor. É com esse foco que ele desenvolve seu pensamento, o que não significa que não seja útil a outras áreas. A própria pesquisa de mestrado que origina este artigo se debruça sobre problemas discursivos no campo da educação, o que atesta a relevância de Gee no âmbito dos estudos do discurso e, mais especificamente, aqueles concernentes à prática educativa, sendo uma importante construção que pode auxiliar pesquisadores interessados nessa temática.

\section{REFERÊNCIAS BIBLIOGRÁFICAS}

CORREIA, K. C. A. "Na prática, a teoria a outra!", uma análise discursiva sobre a responsabilidade social do professor de Português da Educação Básica. 369 f. Dissertação (Mestrado em Letras) - Programa de Pós-Graduação em Letras, Universidade Federal de São João del-Rei, São João del-Rei, 2017.

GEE, J. P. Social Linguistics and Literacies: Ideology in Discourses. London/New York: Routledge, 1996.

GEE, J. P. Identity as an Analytic Lens for Research in Education. Review of Research in Education, Madison, v. 25, p. 99-125, 2000.

GEE, J. P. An introduction to Discourse Analysis: theory and method. London/New York: Routledge, 2005.

GEE, J. P. Discourse Analysis: What Makes It Critical? In: ROGERS, R. (ed.). An Introduction to Critical Discourse Analysis in Education. London/New York: Routledge, 2011, p. 23-45.

PAZ, M. L.; FRADE, C. A História de Nair: a Força da Identidade Institucional para a Permanência na Docência em Matemática. Bolema, Rio Claro, SP, v. 30, n. 56, p. 1260-1279, dez. 2016. 